\title{
Social consequences of infected haemophilia cases in the Islamic Republic of Iran
}

A.M. Cheraghali, ${ }^{1,2}$ P. Eshghi ${ }^{1,3}$ and H. Abolghasemi, ${ }^{1,2}$

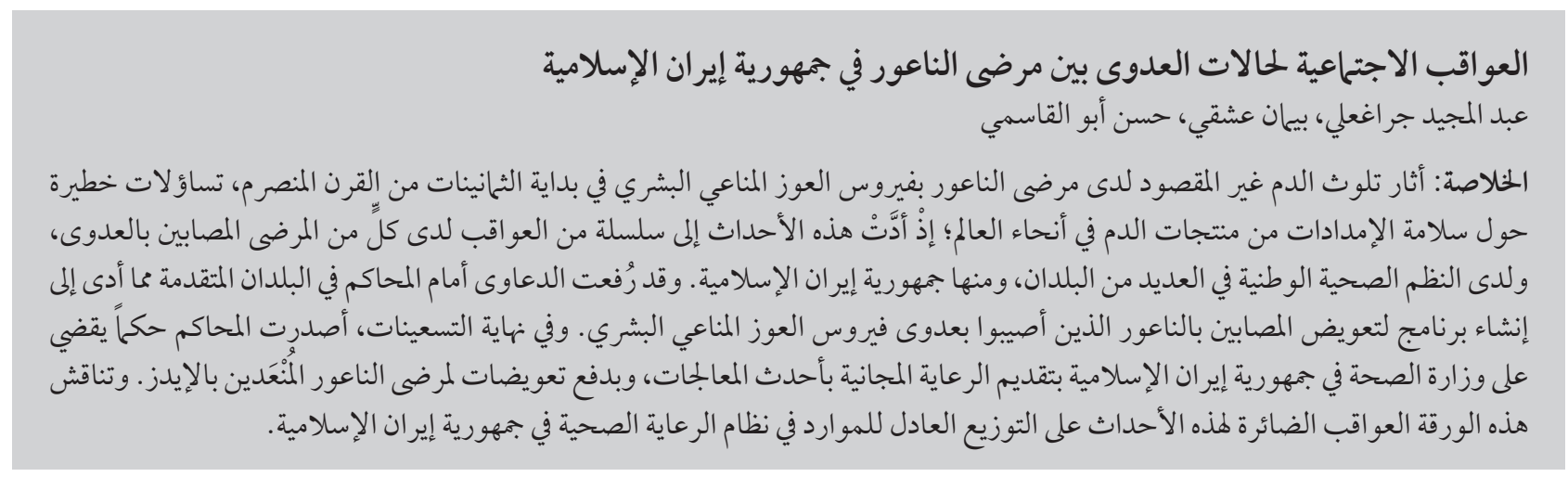

ABSTRACT The unintentional contamination of haemophilia patients with HIV in the early 1980 s raised serious questions about the safety of blood product supplies worldwide. The events initiated a cascade of consequences for both infected patients and the national health systems of many countries, including the Islamic Republic of Iran. Lawsuits have been filed in the courts mostly in developed countries, leading to the establishment of some kind of reimbursement programme for haemophilia patients who acquired viral infections. In the late 1990s the courts ordered the Iranian Ministry of Health, in addition to providing free care with the latest treatments, to pay compensation to the haemophilia patients. The adverse consequences of these events on the equitable distribution of resources in the Iranian health care system are discussed in this paper.

\section{Conséquences sociales de la contamination des patients hémophiles en République islamique d'Iran}

RÉSUMÉ La contamination non intentionnelle des patients hémophiles par le VIH au début des années 1980 a soulevé de graves questions relatives à la sécurité des approvisionnements en produits sanguins dans le monde. Les événements ont déclenché des conséquences en chaîne, à la fois pour les patients infectés et pour le système de santé national de nombreux pays, notamment la République islamique d'Iran. Des procès ont été intentés principalement dans les pays développés, conduisant à l'établissement d'une sorte de programme d'indemnisation pour les patients hémophiles ayant contracté des infections virales. À la fin des années 1990, la justice a condamné le Ministère de la santé iranien à verser des indemnités aux patients hémophiles, en plus de la fourniture de soins gratuits incluant les traitements les plus récents. Les conséquences négatives de ces événements sur la distribution équitable des ressources du système de santé iranien sont détaillées dans le présent article.

'Iranian Blood Transfusion Organization Research Centre, Tehran, Islamic Republic of Iran (Correspondence to A.M. Cheraghali: Cheraghali @ibto.ir).

${ }^{2}$ Faculty of Medicine, Baqiyatallah University of Medical Sciences, Tehran, Islamic Republic of Iran.

${ }^{3}$ Mofid Hospital, Shaheed Beheshti University of Medical Sciences, Tehran, Islamic Republic of Iran.

Received: 16/11/09; accepted: 22/12/09 


\section{Introduction}

Despite a long history of attempts to treat patients using human or animal blood products, modern transfusion medicine only started in the second half of the last century. With the increasing use of these new interventions, it rapidly became clear that these therapeutic approaches also had side-effects such as the incompatibility of red blood cells and plasma between donor and recipient and the risk of transmission of bloodborne pathogens to the recipient.

Current strategies implemented by transfusion services in countries with up-to-date health care systems have significantly reduced the possibility of transfusion-transmitted infections. These include recruiting voluntary non-remunerated donors, donor exclusion criteria, specific and sensitive screening tests, implementing good manufacturing practices in blood handling establishments and in some cases pathogen reduction procedures. While such measures have not been able to completely eliminate all risks of transfusion-transmitted infections from known and, more importantly, emerging pathogens the estimated risk for viral transmission especially in developed countries has been significantly reduced [1]. Unfortunately, due to lack of access in low-resource countries to most of the sensitive and specific screening tests, the safety of blood products in these countries is still a major concern. In some developing countries paid and/ or replacement donors are the main pool of donors and substantial numbers of donations in these countries remain unscreened for viral markers $[2,3]$.

The possibility of transmission of pathogens via blood transfusion had been known since the catastrophic events of the early 1980s, when it emerged that there had been accidental infection of haemophilia patients with human immunodeficiency virus (HIV). This experience began to raise questions about the safety of blood products worldwide and initiated a cascade of consequences for both infected patients and for national health systems in many countries. The Islamic Republic of Iran was no an exception.

Since the early 1980s all transfusion services in the country have been concentrated under a single organization, the Iranian Blood Transfusion Organization (IBTO), which is an integral part of the Iranian national health system. In order to meet the country's blood demands in 2008, the IBTO collected more than 1.8 million units of blood from $100 \%$ voluntary and non-remunerated donors. This indicates a blood donation index of 25 per 1000 population. The IBTO has been successful in improving the national blood safety profile. Screening of blood donations for hepatitis B surface antigen (HBsAg) became mandatory in 1974. Screening of blood units for HIV and hepatitis C virus (HCV) started in 1989 and 1996 respectively. Anti-HIV 1/2 antibody testing was changed to HIV antigen/ antibody combination in 2005. Implementation of a highly efficient donor selection programme, including donor interviews, establishment of a confidential unit exclusion programme and laboratory screening of donated bloods by the IBTO, have led to seroprevalence rates of $0.41 \%, 0.12 \%$, and $0.004 \%$ for hepatitis B virus (HBV), HCV and HIV respectively in donated blood $[4,5]$.

Although the tragedy of infection of Iranian haemophilia patients ignited actions which resulted in improvements to the national transfusion services, it has had grave social and economic consequences for the Iranian health care sector, as discussed in this paper.

\section{Historical background}

Following reports of accidental HIV infection of haemophilia patients in 1982 and other evidence indicating the risk of spread of HBV and HCV infection through contaminated blood products, the blood transfusion services and industries manufacturing plasma-derived medicines underwent major changes worldwide.

Cases of haemophiliacs infected with HIV following administration of contaminated clotting factors led to a number of lawsuits being filed in the courts, mostly in developed countries, against both pharmaceutical companies producing such products and health officials. Such litigation in the 1990s led to the establishment of some kind of reimbursement programme in about 20 countries for haemophilia patients who acquired viral (mainly HIV) infections from tainted blood products supplied in the 1980s. However, despite the attention paid to the consequences of HIV contamination in haemophilia patients, accidental HCV contamination of transfused patients has received relatively little attention. In most of these countries criminal judicial investigations against government and private industry officials were also held. The results of such lawsuits have been discussed previously $[6,7]$. Compensation has also been paid to the infected patients or surviving family members of deceased patients for accidental HIV infection in about 28 countries and for HCV infection in 10 countries [8]. To be eligible for financial compensation, litigants usually renounce their civil rights to any future action against government bodies [6].

In the early 1980s the Islamic Republic of Iran imported most of the clotting factors used in the country from Institut Mérieux, a French pharmaceutical company which is now part of Sanofi-Aventis. Similar products were also sold by the company to other countries in the region, including Iraq. It has been reported that Iraqi officials are now negotiating with the Mérieux and Immuno companies to settle a compensation for Iraqi haemophiliacs who contracted HIV from tainted products distributed by the company in Iraq between 1982 and 1986 [9]. In the Islamic Republic of Iran in the early 1990s a lawsuit 
was filed by a group of haemophilia patients against some of the Iranian officials both in the IBTO and Ministry of Health $(\mathrm{MOH})$, alleging negligence in the screening of blood and blood products. The court later convicted the $\mathrm{MOH}$, requiring them to provide free treatment for patients and also to pay compensation. Although the former head of the IBTO and 3 others officials were also convicted by the court, they have never been indicted. The Islamic Republic of Iran may be the only developing country faced with such a verdict, and it has led to grave consequences for the national transfusion system and public health sector.

\section{Financial consequences}

The Islamic Republic of Iran is a developing country with limited resources available in its health sector. Total per capita expenditure on health in the country is about \$US 700 [10] and this budget is supposed to provide health services for a population of over 70 million with a high prevalence of communicable and noncommunicable diseases including "rare" diseases that only affect a small proportion of the population. Treatment for rare diseases is very expensive and usually takes an unfair slice of the financial resources available in any health care sector. Therefore, in view of national economic constraints and the high rate of serious health problems such as infectious diseases and malnutrition that affect much of the population in developing countries, diseases such as haemophilia are not given priority [11].

Currently there are about 7000 haemophilia patients in the Islamic Republic of Iran [12]. Despite limited resources available in the health sector, Iranian haemophiliacs had access to commercial concentrated coagulation factors shortly after the introduction of these medicines. Due to governmental support, these medicines have always been free of charge. Since the Islamic Republic of Iran did not have a local plasma fractionation facility, except for a very short period in the early 1990s, the country has to rely on imported clotting factors. Therefore the Iranian national health care system has to spend a considerable portion of its limited resources to finance these medicines. Average per capita consumption of factor VIII clotting factor is rising in the country and is now about $1.8 \mathrm{IU}[5]$.

Accidental viral contamination among haemophilia patients around the world has attracted considerable attention to the issue of safety of blood and blood products. Published reports confirm that up to $60 \%$ of haemophilia patients in the developed world contracted HIV through administration of contaminated blood products [6]. However, despite drastic responses to the spread of HIV infection among haemophiliacs and a very high incidence of HCV infection among people with haemophilia, which is reported to be up to $90 \%$ [7], national responses to $\mathrm{HCV}$ contamination of blood supply were fairly mute. In contrast to the example of HIV, no public health official or manager of blood fractionation facilities in the world has been found guilty of criminal charges for HCV contamination of the blood supply in the 1980s. The factors that influenced the different responses of policy-makers to these twin epidemics have been discussed previously [7]. It is argued that the financial consequences for health care are serious if compensation is paid whenever a patient has been treated properly but may later suffer from side-effects [13]. This perhaps has been one the rationales for not convicting officials for decisions related to HCV contamination of the blood supply.

Although there are no published data about the national prevalence of viral markers in multi-transfused patients, including haemophilia and thalassaemia patients, in the Islamic Republic of Iran, the reported data indicates a lower prevalence of these markers in Iranian patients compared with other countries. The prevalence of HIV in Iranian haemophiliacs is reported to be $0.76 \%-2.3 \%[14,15]$. According to a World Federation of Hemophilia report, while $3.6 \%$ of Iranian haemophiliacs contracted HIV, the prevalence of HCV among these patients is about $41 \%$ [8]. Despite the relatively low incidence of HIV and HCV infection in Iranian haemophilia patients compared with those living in developed countries, since the 1990s about 3000 haemophilia patients (42\%) have filed lawsuits against the Iranian national health care system claiming compensation for HIV and HCV infection.

According to the published data the average amount of compensation awarded to infected patients in countries with developed economies ranges from US\$ 37000 to US\$ 400000 for HIV-infected haemophiliacs and from US\$36 000 to US\$ 50000 for HCVinfected haemophiliacs [7]. Compensation paid to patients is usually funded through a joint fund established by the government and pharmaceutical companies involved in manufacturing the blood products. On average the value of compensation paid to each patient in developed economies is about $1-2$ and 2-14 times the gross national product (GDP) per capita for HCV and HIV respectively. However, this figure was more than 10 times GDP in the Islamic Republic of Iran. Comparison between the ratio of compensation and' per capita GDP for the Islamic Republic of Iran and some developed countries is illustrated in Figure 1 $[6,16]$. Up to now the courts have ordered the Iranian national health care sector to provide full treatment free of charge for haemophilia patients with HIV or HCV and also to pay compensation equal to US\$ 31 million to about 1120 patients. About 2000 plaintiffs are still waiting to receive court orders for possible compensation. Although confirmation of the source of contamination in Iranian patients has 


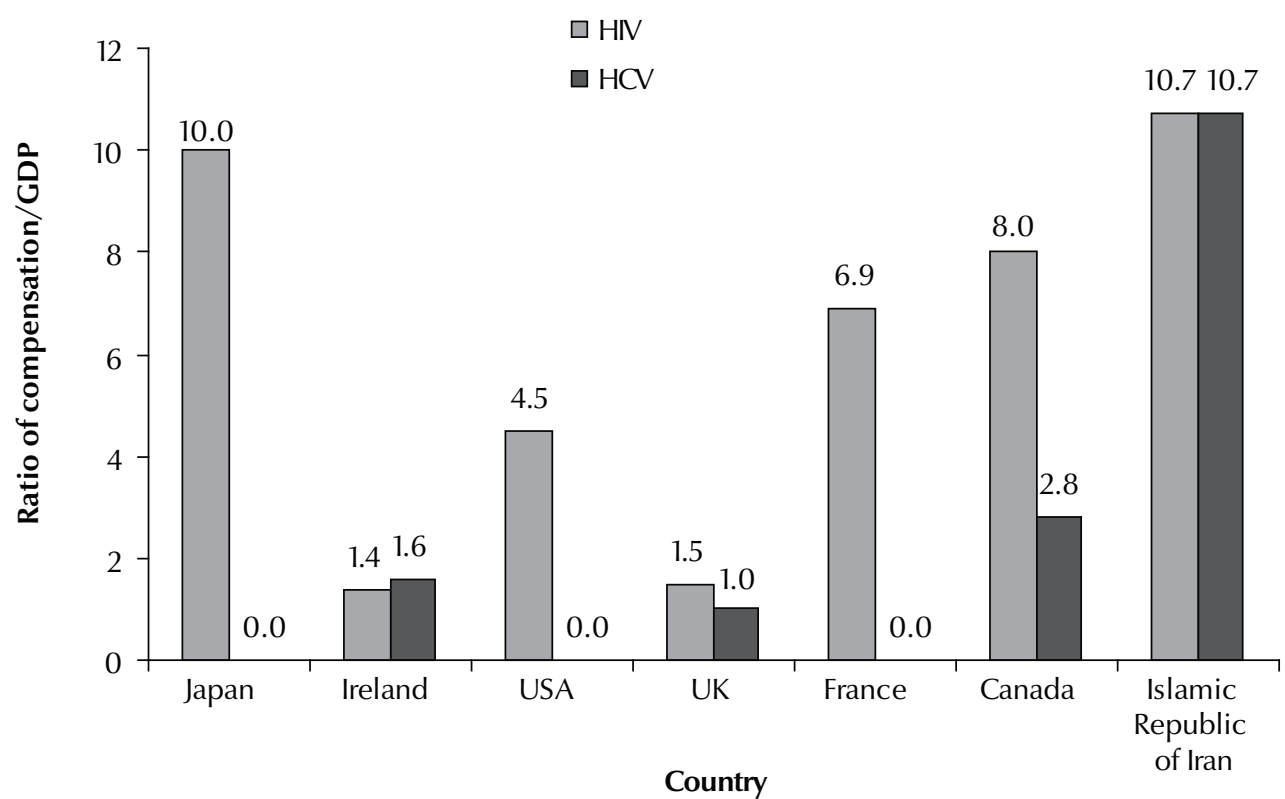

Figure 1 Ratios of compensations paid to haemophilia patients accidentally infected with HIV and/or HCV through contaminated blood products and per capita gross domestic product (GDP) for the Islamic Republic of Iran and some developed countries

never been the concern of the courts, recent publication on the genotype of HIV of Iranian haemophilia patients has raised questions about the source of contamination in these patients and its correlation to blood products produced in the country. The results of studies conducted by the Pasteur Institute of the Islamic Republic of Iran indicated that Iranian hemophilia patients are affected by HIV type B, whereas the HIV patients in the general population of the country are affected by type A virus. Therefore, it may be concluded the HIV affected hemophiliacs in the Islamic Republic of Iran were infected by imported clotting factors [17].

Unfortunately the Iranian $\mathrm{MOH}$ has used the national health care budget to pay compensation to the patients. According to the court order, the $\mathrm{MOH}$ has to use the most recently available medicines for treatment of haemophilia patients with HIV and/or HCV, regardless of their cost-effectiveness. For example, despite the proven efficacy of conventional interferon to treat $\mathrm{HCV}$ infection, the Iranian $\mathrm{MOH}$ is currently using a very expensive pegylated interferon preparation, at no cost to the patients. It is expected that implementing costly but not highly cost-effective procedures or policies in countries with limited resources may result in constraints in other areas of health care and loss of previously realized benefits to a greater number of the population. This might ultimately compromise the golden role of "bringing the greatest good to the greatest number", at least in the field of haemophilia.

The court verdict against the Iranian MOHand IBTO has also compromised people's trust in the national transfusion services. Blood transfusion, as one of the most effective medical interventions, is a unique technology that blends science with altruism. Though the collection, processing and use of blood are technical, its availability depends entirely on the extraordinary generosity of the blood donor who donates the gift of life. Safe transfusion not only requires the application of science and technology to blood processing and testing but also social mobilization to promote voluntary blood donation [3]. Therefore any inappropriate reactions to such activities will reduce volunteers' trust in the national transfusion organizations and the provision of the necessary services to countless patients in need of blood and blood components.

\section{Comment}

Viral contamination of Iranian haemophilia patients through administration of tainted blood products in the 1990s had grave consequences both for the patients and the Iranian national health care system. On the national health care sector side, the MOH has to pay compensation from the national health budget. Obviously this has reduced the per capita share of the budget for all patient groups, including haemophiliacs. Shortage of available resources for investment into someimportant treatmentinterventions, such as immune tolerance induction, secondary and target joint prophylaxis and orthopaedic reconstruction surgery, could compromise patients' quality of life.

Shifting the national health care budget toward a specific patient group 
may also compromise national health equity and ultimately skew the equity distribution curve. Provision of the most expensive medicines and therapies for haemophiliacs in the Islamic Republic of Iran both for treatment of their blood disorder and for viral contamination has increased the share of the national health care budget of these patients to more than 23-fold that of other patients. This might contradict the moral point of view that no community member can claim that his/her interests be advanced to a greater degree than those of any other community member. It is argued that investing substantial amounts of resources for rare conditions does not optimize the benefit to society [18].

In countries with limited resources available to the health care sector, a strategy of lower cost treatment and a holistic approach to patient care with cost-effective utilization of limited resources provides a viable standard of care, especially in the expensive field of haemophilia treatment. The Iranian $\mathrm{MOH}$ now spends its limited resources on less cost-effective interventions for haemophiliacs in order to avoid further confrontation with the courts. The court order against the $\mathrm{MOH}$ in the mid1990s led to the closure of the only national plasma fractionation facility present in the country, which now relies on importation of the expensive coagulating factors to meet patients' needs. This has obviously put new constraints on the limited resources available in the Iranian national health care sector.

Currently the Iranian $\mathrm{MOH}$ has to support treatment of all AIDS patients regardless of the cause of the infection. These patients receive all care, including anti-retroviral treatment, free of charge. Therefore the system is also committed to treatment of HIV-infected haemophilia patients. Unfortunately today haemophilia in the Islamic Republic of Iran is flagged as a problematic and challenging area which most of the time will terminate in a lawsuit. Therefore, few physicians even dare to provide care for these patients. It seems that some of the patient groups in the country, instead offocusing on interventions to improve the quality of life of haemophilia patients, mainly concentrate on filing lawsuits against national health officials. This has caused a lifelong fear of transfusion-transmitted infections regardless of the real risk in comparison with other problems and complications of caring for haemophilia patients. That is why currently more that $45 \%$ of haemophiliacs in the country are in the courts as plaintiffs. Unfortunately this has caused a stand-off between the haemophiliacs and the national health care system, which is supposed to be the main caregiver to these patients. There is no doubt that patients, and their quality of life, will be the main losers of such struggle.

Recent published reports indicate that legal interventions and verdicts have not contributed to patients' quality of life, and in fact the quality of life of Iranian haemophiliacs has been compromised [19-21]. Meanwhile, interventions such as immune tolerance induction, secondary and target joint prophylaxis and orthopaedic reconstruction surgery have been totally ignored by both patient groups and the national health system.

\section{References}

1. Bihl F et al. Transfusion-transmitted infections. Journal of Translational Medicine, 2007, 5:25.

2. Gabriel AS et al. Safety of blood supply for infectious diseases in Latin American countries, 1994-1997. American Journal of Tropcial Medicine and Hygiene, 2001, 65:924-930.

3. Universal access to safe blood transfusion., Geneva, World Health Organization, 2008 (WHO/EHT/08.03).

4. Abolghasemi $\mathrm{H}$ et al. Introduction to Iranian Blood Transfusion Organization and blood safety in Iran. Iranian Journal of Public Health, 2009, 38(Suppl. 1):82-87.

5. Cheraghali AM. Availability of blood components and plasma derived medicines in Iran. Transfusion and Apheresis Science, 2007, 37:3-7.

6. Weinberg PD et al. Legal, financial, and public health consequences of HIV contamination of blood and blood products in the 1980s and 1990s. Annals of Internal Medicine, 2002, 136:312-319.

7. Angelotta $C$ et al. Legal, financial, and public health consequences of transfusion-transmitted hepatitis $C$ virus in persons with haemophilia. Vox Sanguinis, 2007, 93:159-165.

8. Report on the annual global survey 2004. Montreal, World Federation of Hemophilia, 2005,

9. Zelbauer P. Iraqis infected by HIV tainted blood try new tool: a lawsuit. New York Times, September 2006.

10. World health statistics 2008: Iran (Islamic Republic of). World Health Organization [website] (http://www.who.int/countries/irn/en/, accessed 27 April 2011).
11. DiMichele D et al. Ethical issues in haemophilia. Haemophilia, 2006, 12(Suppl. 3):30-35.

12. Mehdizadeh $\mathrm{M}$ et al. Occurrence of haemophilia in Iran. Haemophilia, 2009, 15:348-351.

13. Dyer C. Justice versus equity for haemophiliacs with AIDS. British Medical Journal, 1990, 301:776.

14. Rezvan $\mathrm{H}$, Abolghassemi $\mathrm{H}$, Kafiabad SA. Transfusion-transmitted infections among multitransfused patients in Iran: a review. Transfusion Medicine (Oxford, England), 2007, 17:425-433.

15. Sharifi-Mood B et al. Hepatitis B and C virus infections in patients with hemophilia in Zahedan, southeast Iran. Saudi Medical Journal, 2007, 28:1516-1519.

16. World statistics. NationMaster [website] (www. nationmaster. com, accessed 27 April 2011).

17. Sarrami-Forooshani $R$ et al. Molecular analysis and phylogenetic characterization of HIV in Iran. Journal of Medical Virology, 2006, 78:853-863. doi:10.1002/jmv.20634.

18. Hughes DA, Tunnage B, Yeo ST. Drugs for exceptionally rare disease: do they deserve special status for funding? Quarterly Journal of Medicine, 2005, 98:829-836.

19. Karimi $\mathrm{M}$ et al. Health status in Iranian haemophilic patients. Haemophilia, 2008, 14:615-617.

20. Hoorfar H, Mobaraky G. Quality of life in severe hemophilia in Esfahan. Haemophilia, 2006, 12(Suppl. 2):122 [abstract].

21. Karimi $M$ et al. Substance dependency in Iranian patients with hemophilia. Addictive Behaviors, 2007, 32:365-369. 